\title{
Application of Building Material in the Room Decoration
}

\author{
Muhui Wu*, Qiong Nie, Zhengxiang Wu \\ School of Construction and Materials Engineering \\ Hubei University of Education \\ Wuhan, China \\ wumuhui313@aliyun.com
}

\begin{abstract}
Room decoration is the recreation activity carried out by the architect in a given building space. It is the treatment for the interior space provided by a building, and specifically, it refers mainly to the ceiling, wall and floor in enclosed interior space. The paper focuses on the application of building material in room decoration: steering people towards better decisions by presenting choices on design forms, function requirements, price levels etc. in the room decoration of the ceiling, wall and floor, and expressing the opinion on the following four aspects: classification, properties, material uses and psychological association.
\end{abstract}

Keywords- building material; room decoration; material classification; material property; material application

\section{INTRODUCTION}

Room decoration is a kind of environmental and architectural art which purpose to create beautiful indoor environment. It combines of architectural elements, building materials, color, shadow and furnishings for beautiful, practical and individual artistic effect.

Room decoration discussed in this paper referring mainly to the ceiling, wall and floor in enclosed interior space. Application of building material in the room decoration is discussed in detail below.

\section{DECORATIVE MATERIALS OF CEILING}

Ceiling is the most variegated and remarkable covering part in interior space, although it cannot be touched or leaned on. It should be noted because it is not only the structure of the building, but also the building block used for burying pipelines and fixing lamps.

First of all, notice the lightness of ceiling sculpture while meeting the requirements of the structural safety and equipment arrangements. Air-condition and light-current control system should be properly disposed in the ceiling. As well as the coordination of vent, smoke detector, auto sprinkler with the surface of the ceiling.

Forms of the ceiling: flat, suspension, grillage, Concave-convex, stars, wall and knitting types.

The requirements of maintenance materials are good fire proof performance, lightweight and low cost. Commonly used are:

1. Gypsum plasterboard: it is of good flatness, low cost, easy installation, but susceptible to water. It cannot be used for the bathroom ceiling.
2. Fibreboard: it is of low cost but poor quality, and it is suited for low grade decoration.

3. Plywood: thinner and yieldingness, and it is topically used for curved ceiling.

4. Density board: good flatness, high cost, and it is commonly used for all sorts of modeling of ceiling.

The facing material of ceiling is applied on soffit and wall material. Commonly used are:

1. Dope series: it refers to emulsion paint with low cost and extensive uses.

2. Pasting series: typically wallpaper, which is difficult to constructed, and applied only for small areas.

3. Plank series: it refers to Beech, Rose wood, Sapele, or metal lining such as Stainless steel, Tempered Glass and Color board. In particular, the plastic plate has excellent art effect and high price.

During construction, some facing material with integrated decorative surface can be installed together with the keel, avoid having to use an additional cover material. For example, mineral wool decorative acoustic board, gypsum decorative acoustic board, asbestos decorative acoustic board, metal microporous, plastic gusset plate and mirror glass.

\section{DECORATIVE MATERIALS OF WALL}

Wall material sites in easy-to reach area and occupies an important place because it is perpendicular to the viewer. Therefore, wall material has a great influence on the indoor space.

The design forms are: three-stage, integral, and three dimensional types. The materials are:

1. Plastering series: including galling, bracing, brushing, sprinkling, spraying materials. It is economical, practical with a strong decorative effect.

2. Dope series: Emulsion Paint and Water soluble paint.

(1) Emulsion Paint: as scrub and god decorative effect, is the preferred wall material for dry regions.

(2) Water soluble paint: cannot powder, low cost, easy construction, used to paint the walls.

3. Coil series: including wallpaper, wall cloth, leather and artificial leather, used for all sorts of internal wall.

(1) Wallpaper: various patterns and colors, absorbs sound and easy to clean.

(2) Wall cloth: low cost, variety, moisture-absorbing, non-toxic and odorless, sound-absorbing, bright in color. 
(3) Leather and artificial leather: softness, feel good, soundproof and heat resistant, suit for upscale interior.

4. Veneer series:

(1) Stone: it mainly refers to Marble (easy eroded) or Granite (weather-resistant) which are hard, durable, bright in color, solemn generous, with natural and ruggedly texture and beauty of toughness.

(2) Facing brick: it refers to glazed and unglazed brick. It is water and fire resistant which are generally used in the high humidity area such as kitchen and washroom.

5. Flitch series:

(1) Gypsum board: light quality, adiabatic, sound absorption, non-combustion, convenient machining. It can be used as a partition together with light steel keel.

(2) Wood: light quality, high strength, flexible, toughness. It can be processed into plywood, density board, fibreboard and used for different level decoration. It's beautiful natural texture cannot be replaced by other materials.

(3) Mirror glass: it can increase the dimensional result on the vision and create gorgeous and elegant atmosphere, especially in a small room.

(4) Metal plate: including stainless steel plate, titanium plate, aluminum-plastic composite plate, aluminium alloy plate, steel plate and copper plate. The features are: long serving life, hard texture, strong era sensation and high price. It commonly used in the public building wall.

(5) Wood lath or bamboo cane: it makes you feel warm, graceful, natural, guileless and friendly.

\section{DECORATIVE MATERIALS OF FLOOR}

Floor is the fundamental plane in interior space, as a bearing platform for indoor activity and furnishings. We perceive the variation of its texture, color and pattern during chamber events. The function of floor decoration should be considered firstly since it is the foundation of pattern design for the patter, shape, range and size of floor paving. Secondly, the design should be merged into the overall space to the satisfaction of visual demand and appropriately foil the interior environment atmosphere.

The design forms are: flat floor and platform. Decorative materials on floor are:

1. Wood floor:

(1) Solid wood flooring: it is overhead, played in the cage, elastic, simple and comfortable.

(2) Laminate flooring: confluent, non-elastic, hard and durable.

2. Stone floor: familiar ones are marble and granite. It has the characteristics of good resistance, hard, highabrasive, durable, pretty and clam appearance, colorful, glabrous and good-looking. It is an ideal material for entrance hall and dining room.

3. Floor tile: it is fall into two categories: glazed and unglazed with shapes of square and hexagonal. Glazed stone floor looks bright and clean. The features are finegrained, high-abrasive, resist to acid and alkali, easy to clean, water proof and anti-dust. It commonly used in kitchen or wash room.

4. Terrazzo floor: it is divided into normal and art terrazzo. It is cast-in-situ or prefabricated. It normally used in hall, corridor and stairs due to its good integrality, profoundly malleable and great design effect.
5. Plastic floor: it is made of massive material with organic materials as the main ingredient or coiled material. The features are good-looking, soft, high-abrasive, bright and clean, lower noise, good insulation quality, easy replacing and low cost.

6. Carpet: it is made of pure wool, blending poly fibers, plastic or straw. It is sound-absorbing, slip-resistant, soft, comfortable, colorful, and graceful.

7. Mosaic floor: it looks bright, clean, beautiful and hard and commonly used in hall, corridor, dining room, kitchen room and wash room.

\section{PSYCHOLOGICAL ASSOCIATION OF DECORATIVE MATERIAL}

The interface of interior space plays the role in accompaniment. It cannot be strongest part in a room so as not to affect the coordination of the whole space. Therefore, the feature of the decoration should be dominated by simple, bright and elegant. It is important to note the psychological association of decorative material. For example:

1. Large area of paint material: feels like clean, tidy, gentle and quiet.

2. Large area of paper material: feels like quiet and rhythmic.

3. Clear texture bamboo vine: feels like natural and simple.

4. Cotton, hemp, wool, leather and silk material: feels like soft, light, graceful, warm and friendly.

5. Mirror glass: feels like openness and gorgeous.

6. Stainless steel plate and metal surface: feels like hard and cold.

7. Large area of marble: feels like elegant and noble.

8. Large area of ganged brick wall: feels like endless nostalgia.

Different wood materials can arouse different feelings:

1. Rose wood: clam and noble.

2. Oak: rough and heroic.

3. Pink ivory: fine and elegant.

4. Juniper: smooth and fine.

5. Beech wood: texture and peaceful.

6. Maple: texture and micromesh.

7. Teak wood: classic and pomposo.

8. Redwood: noble and elegant.

In a word, the building material is the base of decorative project. The selection of the material can affect the function, formal expression, decorative effect and quality of construction. Therefore, building materials should be properly applied according to their characteristics during the decoration.

\section{ACKNOWLEDGMENT}

This work was financially supported by the teaching research project of Hubei Provincial Department of Education ("Research and Practice on the Training Mode of Applied Talents in Construction Engineering", NO. 2013391).

\section{REFERENCES}

[1] Zhan-tai R. Application of Environment Friendly Building Materials in Residential Housing[J]. Research \& Application of Building Materials, 2011.

[2] Yan G. The application of Chinese traditional patterns in carved building[J]. Shanxi Architecture, 2012. 
[3] Wei T. Application of PVC floor in the building decoration[J]. Shanxi Architecture, 2012.

[4] Kuai L. The application of folk building art in modern interior design[J]. Shanxi Architecture, 2005.
[5] Jia Q, Zhou Y, Shen Y N. On the Application of Decoration Materials in Architecture[J]. Architecture Building Materials \& Engineering Management, 2013. 